\title{
Mentorship in academic radiology: why it matters
}

\author{
Miriam A. Bredella ${ }^{1 *}$ D, David Fessell ${ }^{2}$ and James H. Thrall ${ }^{1}$
}

\begin{abstract}
Mentorship plays a critical role in the success of academic radiologists. Faculty members with mentors have better career opportunities, publish more papers, receive more research grants, and have greater overall career satisfaction. However, with the increasing focus on clinical productivity, pressure on turn-around times, and the difficult funding climate, effective mentoring in academic radiology can be challenging. The high prevalence of "burnout" among radiologists makes mentorship even more important. This article reviews benefits and challenges of mentorship in academic radiology, discusses how to institute a faculty mentoring program, examines different types of mentoring, and reviews challenges related to diversity and inclusion.
\end{abstract}

Keywords: Mentoring, Radiology, Faculty, Burnout, Job satisfaction

\section{Key points}

- Mentorship plays a critical role in the success of academic radiologists

- Mounting pressures on academic radiologists in a changing healthcare environment can lead to physician burnout

- Mentoring is an effective means to achieve career satisfaction and help prevent burnout

- Establishing a mentoring program in academic radiology requires the identification and training of effective mentors, and mentees benefit from multiple mentors for different needs

- Women and underrepresented minorities in medicine often do not have access to mentors but benefit most from a mentoring relationship

\section{Introduction}

Mentorship plays a critical role in the success of academic radiologists. A mentor helps a mentee reach both personal and career goals by functioning as an adviser and role model while providing support and sharing knowledge [1]. Multiple studies have shown that faculty members with mentors have better career opportunities, publish more

\footnotetext{
* Correspondence: mbredella@mgh.harvard.edu

1 Department of Radiology, Massachusetts General Hospital and Harvard

Medical School, Yawkey 6E, 55 Fruit Street, Boston, MA 02114, USA

Full list of author information is available at the end of the article
}

papers, are more likely to receive research grants, and have greater overall career satisfaction [2-6]. The benefits of mentorship go both ways: while mentees benefit from professional support, advice, and career-specific skills, mentors receive intellectual and professional stimulation, personal enrichment, and a sense of giving back to their institutions and specialty $[7,8]$. Moreover, reverse mentoring, where mentees provide skills and guidance to their mentors, can be beneficial to the mentor, for example in the use of social media, often more familiar to younger mentees [9]. At an institutional level, mentorship offers the opportunity to develop future leaders in clinical care, research, education, and administration [8], and institutions with successful mentoring programs have better clinical and academic productivity, better retention and academic promotion rates $[10,11]$.

While most radiology residency programs have incorporated formal mentoring programs for residents $[4,5,12-$ 14], fewer departments have instituted mentoring programs for junior faculty $[15,16]$. Junior or newly hired faculty in academic radiology face specific obstacles including new clinical, educational, and research responsibilities, often paired with personal changes and growing family demands $[16,17]$. In addition, the increasing focus on clinical productivity, pressure on turn-around times, and demands on non-interpretive tasks, such as consultations, administration, meetings, and teaching [18-20], have led to a high prevalence of "burnout" among 
radiologists [21], making mentoring of junior faculty members even more important.

This article reviews the benefits and challenges of mentorship in academic radiology, discusses how to institute a faculty mentoring program, examines different types of mentoring, and reviews challenges related to diversity and inclusion.

\section{Why mentorship in academic radiology matters more than ever}

A career in academic radiology requires balancing competing demands from clinical work, education, and research. Reasons for junior faculty to embark on a career in academic radiology include opportunities for teaching, research, and having an interesting mix of clinical cases, while deterrents include insufficient financial compensation, lack of academic time, high clinical workload, and the long time for promotion [22]. Most faculty who leave academics do so within the first years; therefore, efforts should be concentrated on retaining junior faculty through effective mentoring to address the following challenges.

\section{Mounting pressures on academic radiologists in a changing healthcare environment}

Academic radiology has experienced major changes over the past decades [23], with increasing imaging volumes coupled with lower reimbursement rates [24], pressure on shorter turn-around times (TAT), and growing demands on non-interpretative tasks [18, 19, 25]. The average workload of radiologists as measured by annual relative value units (RVUs) per radiologist has increased by $70 \%$ over the last 25 years [18], and this increase was coupled with lower TAT. In fact, low TAT has been among one of the highest priorities in academic medical centers [20]. In addition to the increasing interpretative demands, non-interpretative demands, such as consultations, presentations during multidisciplinary conferences, meetings, training of technologists, and requirements for resident supervision, are rising. A study by Dhanoa et al. has shown that radiologists spend only about half of their time on clinical activities and the remaining time is spent on non-interpretive tasks [19]. Furthermore, decreasing autonomy associated with practice standardization, structured reporting, evidence-based recommendations, procedural checklists, and increasing dependence on integrated information technology systems [26], place academic radiologists at an increased risk of burnout [21, 27]. These challenges indicate the need for dedicated mentoring of radiology faculty as mentoring has been shown to help prevent burnout in radiology [28, 29].

\section{Challenges of junior faculty members to focus on} academic career development

Junior and new faculty members typically focus on managing the clinical workload, trying to "survive" in a new hospital system with new colleagues and often growing family responsibilities [17], with little emphasis on their academic career development. Because of economic pressures, junior faculty members usually have less protected academic time compared to their senior peers [30]. In these circumstances, mentorship becomes critical in helping junior faculty to improve their clinical efficiency and to guide them in their professional and personal development, including academic promotion [31]. Academic promotion is an important goal for junior faculty. Promotion not only represents a formal marker of academic success but may also lead to additional salary and benefits [30]. Junior faculty members often lack the knowledge of promotion criteria within their institution and benefit from mentoring to better identify their academic track and area of expertise, guidance on which academic activities to focus, and advice on whether they are ready to be promoted. In fact, $98 \%$ of academic physicians cited a lack of mentoring as the largest or second largest factor in hindering career progress [32].

\section{Grant funding climate}

While most academic radiologists who do research are "clinician scholars" who are not dependent on external funding, a small percentage of academic radiologists are able to obtain government or industry-funded grants [30]. Such funding supports the development, testing, and dissemination of innovative new imaging technologies and is crucial to advance our field [33, 34]. The primary source of grant funding in the USA is the National Institutes of Health (NIH). NIH grants are highly competitive, and only a small number of NIH grant applications receive funding [35]. Junior faculty without prior track records of research success face a steep challenge in getting past the threshold of obtaining their first grants, an important step in establishing independent research careers. Declining funding combined with a shift to multidisciplinary, collaborative team-science, requires mentoring programs to support early-stage investigators [36-38]. Mentors with track records of success in obtaining grants are invaluable in helping junior faculty in understanding the ins and outs of grant structure and grant writing and grantsmanship.

\section{Lack of training in professionalism}

Over the last decade, there has been an increasing focus on professionalism in academic medicine. Teaching and assessing competence in professionalism is now an explicit expectation for Accreditation Council Graduate 
Medical Education (ACGME) accredited programs in radiology [39]; however, this topic often receives little attention beyond residency. Unprofessional conduct by radiologists, including conduct leading to prison sentences, has emphasized the need for education and mentorship in professional conduct. Over the past years, radiologists have pled guilty to bribery, fraudulent billing, unlawful prescription of controlled substances, and submission of fraudulent expense reports [40]. This highlights the need for discussions around professionalism by mentors and role models beyond compliance with policies and procedures [40].

Generational differences, increased diversity in the workforce, and the use of social media can also add to misunderstandings of professional conduct [41]. Moreover, the patient-doctor relationship has changed from paternalistic medicine to patient-centered, with patients being encouraged and empowered to control the direction of their care $[41,42]$. The use of the Internet, websites, chat rooms, and blogs by patients and their families, to acquire and share information, can pose challenges in professionalism. Radiologists need to behave appropriately and respectfully in digital and social media, and mentors are needed more than ever to teach the appropriate use of social media, patient confidentiality, and digital professionalism [41].

The current healthcare climate poses several challenges to academic radiologists. Successful mentoring is more important than ever for retaining and managing the current and upcoming demands of junior faculty, and to ensure the future of radiology [7].

\section{Establishing a faculty mentoring program in academic radiology}

Several studies have examined key components of a successful mentoring program in academic radiology $[3,7$, $8,15,43]$. A mentoring program must be customized to meet the specific needs of the faculty to make sure that the experience is rewarding for both mentors and mentees, rather than an obligation [15]. The identification and training of potential mentors are crucial for the success of a mentoring program [44, 45]. An important concept of mentoring in academic radiology is that one mentor cannot do it all and mentees need to assemble a mentorship team [46]. In our mentoring program for junior faculty in the department of radiology at the Massachusetts General Hospital (MGH), we encourage mentees to create a mentorship "Board of Directors," tailored to the unique needs of each faculty member. A diverse group of mentors can provide the mentee with a wide range of perspectives related to research, administration, and clinical expertise and allows networking and development of mentorship relations when one does not need anything in return. Mentees are also encouraged to reach out to mentors from different departments and institutions, also outside of medicine. For this purpose, the Department of Radiology at MGH provides funds for mentees to take potential mentors out to lunch or dinner. This support has eliminated a financial barrier to less formal, more social mentor-mentee interactions, strengthening relationships.

Setting clear expectations for mentors and mentees, reviewing a mentorship agreement which states the ground rules of the mentorship relationship, and creating a career development plan with short- and longterm goals, which can be revisited during the mentoring meetings, are key components of our mentoring program. Additional goals of the program are academic promotion and preparing mentees for the annual career conference with their division heads. In this regard, mentors and mentees receive dedicated lectures and written material on promotion criteria and how to make the best of their annual career conference.

Regular meetings among the mentees of our program help to exchange ideas and allows for peer-mentoring. We also provide funds to help junior faculty members to hire medical students or college students to help with research and scholarly projects. These interactions give the mentees the opportunity to become mentors themselves for college or medical students.

Finally, assessment of the overall effectiveness of a mentoring program can be obtained through evaluations on career satisfaction, attrition rates of junior faculty, promotion, research-related metrics, such as the number of scientific publications, scientific talks, and grant submissions, teaching-related metrics, such as the number of courses taught and educational publications, and clinical-related metrics, including the development of new clinical care and participation in clinical committees. Feedback from these evaluations can help radiology departments to understand the value of mentorship and allows them to tailor their resources to provide effective support to junior faculty.

\section{Mentors}

The identification and preparation of effective mentors are key to the establishment of a successful mentoring program $[3,43]$. Several studies have explored the characteristics of good mentors and interactions with their mentees [3, 32, 47]. Good mentors should be honest, collaborative, and accessible. A well-established position within the academic community that allows professional and networking opportunities for the mentee, professional, and life experiences that can guide mentees in academic and personal decisions, are additional key attributes of a good mentor. Mentors are also expected to provide guidance in dealing with colleagues and institutional "politics" [31]. Mentors should actively seek 
feedback from the mentee to determine what is working in the relationship and what needs to be addressed [4]. Preparation and training of potential mentors include the distribution of written material and participation in mentorship-focused seminars [11].

The main barrier to becoming a mentor is lack of time $[11,14,16]$, often restricting the number of mentees a mentor can have to 2 or 3 [13]. A potential downside for mentors is the time spent on mentoring projects which may be less relevant to the mentor, taking time away from performing more advanced projects, necessary to advance the mentor's career [48]. Including alumni as mentors who do not face the pressures of internal faculty, can help to increase the pool of mentors [14]. Providing protected time and resources to mentors will increase the likelihood of success and sustainability of a mentoring program [11]. Formal recognition of mentors for their time and effort and an emphasis on mentoring during the annual career conference and assessment for academic promotion will also help to motivate potential mentors to participate in mentoring [16].

Malignant mentor behaviors have been described by Chopra et al., which include taking the mentees' ideas and labeling them as their own, exploiting the mentee by giving them low-yield activities that are not advancing their careers, or dominating the mentee, not allowing input from others, which can lead to isolation of the mentee [49]. Those behaviors are often due to distraction, time constraints, and avoiding feedback, even if constructive criticism is necessary [49]. Many of these problems can be resolved or avoided through mentor and mentee education and open communication and the creation of a mentorship team. However, if necessary, mentees should not be afraid and be supported to change mentors if their needs are not met $[8,32]$.

\section{Mentees}

Mentees play a critical role in the success of the mentormentee relationship, and mentees need to be instructed about what is expected from them. This can be accomplished through seminars and the distribution of written material prior to entering into a formal mentoring relationship. Studies have indicated that mentees should be proactive and should take initiative for the mentoring relationship [3,50]. They should be prepared with an outline of the topics they would like to discuss, complete tasks that were agreed upon, and be receptive to feedback [3, 51]. The goal for the mentee is to advance personally and professionally, remain independent and goal-oriented.

Mentee missteps often stem from uncertainty about their responsibilities and the mentors' failure to address them. Vaughn et al. described common mentee missteps and solutions on how to overcome them [52]. Awareness of these pitfalls and proactive mentee education can not only prevent failure but also boost the progress of the mentor-mentee relationship [52].

\section{Matching mentors and mentees}

Identifying helpful mentors for junior and newly hired faculty is key to a successful transition to a new faculty position [8]. However, identifying mentors can be challenging for young and new faculty members who may have limited interactions with senior colleagues beyond their own division [16]. For these reasons, early implementation of mentorship strategies and identification of mentors will help improve the integration of junior and newly hired faculty $[8,16,43,53]$.

Several ways to match mentors and mentees have been described, ranging from self-selected to assigned mentors [54]. The importance of having the right "chemistry" has been stressed by participants in mentoring relationships [32] and participants were more willing to engage in a mentoring program if the personalities matched [55]. Some programs pair mentees with mentors within their own department and division, whereas others, especially smaller programs, suggest mentorship outside the department and division, and even outside of the institution [11].

In our radiology mentoring program at the $\mathrm{MGH}$, we pair junior faculty members with mentors outside of their division. Mentees often already have mentors within their division and having mentors in the same division can lead to conflicts of interest regarding shared or needed resources or when conflicts arise within the division. Pairing mentors and mentees across divisions also fosters better communication within the department. Pairing of mentors and mentees occurs with input from the mentor and mentee with guidance from the director of the mentoring program. The director of the mentoring program meets with each mentee and suggests potential mentors based on the right chemistry and needs. Both, mentors and mentees, have input in the final pairing.

Some programs prefer a more natural matching process by which mentees independently choose their own mentors $[11,15]$. Mentees can be paired with a single mentor [15] or choose several mentors [56]. While we pair the mentee with a single mentor primarily based on chemistry, mentees are encouraged to reach out to other mentors and create a mentorship "Board of Directors," tailored to the unique needs of each faculty member. Developing a network of mentors within and outside of the department, and even outside of medicine, such as in business or government, may help junior faculty members to gain diverse perspectives related to radiology, health care, and administration. Active membership in national radiology societies can also provide 
junior faculty members with a network for connecting with mentors worldwide [16].

\section{Peer mentoring}

While mentorship is often viewed as a dyad with a senior mentor and a junior mentee, peer-mentoring, which encourages junior faculty members of similar rank to collaborate and exchange ideas, is an important part of a mentoring program. Because of the inherent equality of the participants who are often at similar stages in their personal life, participants are often more comfortable discussing professional and non-professional topics, such as the balance between work and family [57]. Moreover, these relationships offer more personal feedback and friendship than traditional mentoring relationships [8]. Peer-mentoring has been shown to improve support, collaboration, and access to resources [58, 59]. Therefore, mentoring programs should encourage radiologists to identify peers within and outside of the department and create formal opportunities for peer-mentoring.

\section{Speed mentoring}

Speed mentoring is an organized event in which a junior faculty member is paired with six senior faculty members for a series of 10-min encounters [60]. A speed mentoring event was offered during the Association of University Radiologists (AUR) Annual Meeting, to improve access to mentorship for clinician educators in radiology [61]. The speed mentoring event created the opportunity for mentors and mentees from geographically diverse academic institutions to network with each other. In addition, mentees had the opportunity to reach out for additional remote mentorship beyond the speed mentoring event. Following the event, both the mentors and mentees felt a stronger sense of community and inclusiveness and felt more connected to the AUR [61].

\section{Mentoring underrepresented minorities in medicine and women}

Women are underrepresented in the radiology workforce and women only occupy a minority of leadership positions without a significant change over the last decade $[62,63]$. The paucity of female leaders in radiology results in a lack of role models and deters women to choose radiology as a career [64].

Female faculty members are less likely to advance academically than their male colleagues of comparable seniority [65]. Demands in clinical workload combined with family obligations and lack of mentoring are factors that hamper the academic careers of women [66, 67]. A major barrier to the academic advancement of women is a lack of role models and mentors, however, mentorship is particularly crucial for women to achieve academic promotion and advance their professional careers [68].
However, the number of women interested in mentorship often outnumbers the number of women who are available or feel qualified [69]. Although women, in general, do not seem to prefer female mentors, they may seek out female mentors for specific advice, including on how to best juggle work and family responsibilities, especially in fields where women are still in the minority, such as radiology [70]. Innovative traditional and peermentoring programs to promote gender equity have been developed [57, 63, 68, 69], such as the Leadership Intervention to Further the Training of Female Faculty (LIFT-OFF) aimed at women radiologists to achieve academic success and assume leadership positions [63].

Mentoring is particularly important for the success and retention of faculty underrepresented in medicine (URiM) [71, 72] who may have limited access to mentors and often face additional challenges, such as bias, prejudice, lack of confidence, and the feeling of isolation, which can lead to attrition from academic careers [73]. For URiM faculty, finding a mentor of similar background is challenging. The race is often cited as an obstacle for mentoring, and URiM faculty reported difficulties in explaining their own racial context to a non-minority mentor [74].

Radiology departments should identify a diverse group of mentors who are able to meet the needs of a diverse faculty. Providing a network of diverse mentors is key to a successful and inclusive mentoring program that is able to provide equal opportunities and advancement to all faculty.

\section{Conclusion}

Mentorship in academic radiology is more important than ever given the mounting pressures of a changing healthcare environment. Mentorship for junior faculty promotes job satisfaction and career advancement, helps avoid burnout, and increases faculty retention. While mentorship is traditionally viewed as a senior mentor and a junior mentee, diverse mentorship teams and peer-mentoring are important components of a successful mentoring program. Academic institutions should recognize the value of mentoring and ensure equal opportunities and advancement of a diverse faculty.

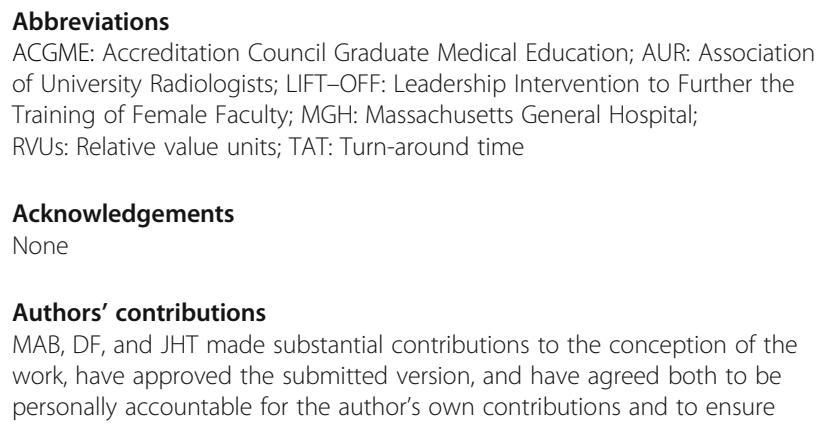


that questions related to the accuracy or integrity of any part of the work, even ones in which the author was not personally involved, are appropriately investigated, resolved, and the resolution documented in the literature. All authors read and approved the final manuscript.

\section{Funding}

The authors declare that this work was supported by NIH grant K24 DK109940.

\section{Availability of data and materials \\ Not applicable}

\section{Ethics approval and consent to participate}

Not applicable

\section{Consent for publication}

Not applicable

\section{Competing interests}

The authors declare that they have no competing interests.

\section{Author details}

${ }^{1}$ Department of Radiology, Massachusetts General Hospital and Harvard Medical School, Yawkey 6E, 55 Fruit Street, Boston, MA 02114, USA.

${ }^{2}$ Musculoskeletal Division, Taubman Center, University of Michigan, Room

2910K, 1500 E Medical Center Drive, SPC 5326, Ann Arbor, Ml 48109, USA.

Received: 8 August 2019 Accepted: 26 September 2019

\section{Published online: 15 November 2019}

\section{References}

1. Bhagia J, Tinsley JA (2000) The mentoring partnership. Mayo Clin Proc 75(5): 535-537

2. Chew LD, Watanabe JM, Buchwald D, Lessler DS (2003) Junior faculty's perspectives on mentoring. Acad Med 78(6):652

3. Sambunjak D, Straus SE, Marusic A (2006) Mentoring in academic medicine: a systematic review. JAMA 296(9):1103-1115

4. Slanetz PJ, Boiselle PM (2012) Mentoring matters. AJR Am J Roentgenol 198(1):W11-W12

5. Sundgren PC (2012) Mentoring radiology residents in clinical and translational research. Acad Radiol 19(9):1110-1113

6. Ward EC, Hargrave C, Brown E, Halkett G, Hogg P (2017) Achieving success in clinically based research: the importance of mentoring. J Med Radiat Sci 64(4):315-320

7. Kostrubiak DE, Kwon M, Lee J et al (2017) Mentorship in radiology. Curr Probl Diagn Radiol 46(5):385-390

8. Retrouvey M, Grajo JR, Awan O et al (2019) Transitioning from radiology training to academic faculty: the importance of mentorship. Curr Probl Diagn Radiol. https://doi.org/10.1067/j.cpradiol.2019.02.011. [Epub ahead of print]. PMID: 30904346

9. Waljee JF, Chopra V, Saint S (2018) Mentoring Millennials. JAMA 319(15): 1547-1548

10. Trossman S (2013) Better prepared workforce, better retention: programs illustrate the value of mentoring. Am Nurse 45(4):1 12

11. Kashiwagi DT, Varkey P, Cook DA (2013) Mentoring programs for physicians in academic medicine: a systematic review. Acad Med 88(7):1029-1037

12. Donovan A (2010) Views of radiology program directors on the role of mentorship in the training of radiology residents. AJR Am J Roentgenol 194(3):704-708

13. Mainiero MB (2007) Mentoring radiology residents: why, who, when, and how. J Am Coll Radiol 4(8):547-550

14. Yedavalli VS, Shah P (2019) Residents' perceptions of usage of the current alumni and attending network for a formal mentorship program in an academic affiliated community hospital radiology residency. Curr Probl Diagn Radiol 48(2):105-107

15. Illes J, Glover GH, Wexler L, Leung AN, Glazer GM (2000) A model for faculty mentoring in academic radiology. Acad Radiol 7(9):717-724 discussion 25-6

16. Perry RE, Parikh JR (2017) Mentorship of junior faculty members in academic radiology. J Am Coll Radiol 14(10):1341-1344

17. Gustin J, Tulsky JA (2010) Effective "on-boarding": transitioning from trainee to faculty. J Palliat Med 13(10):1279-1283
18. Bhargavan M, Kaye AH, Forman HP, Sunshine JH (2009) Workload of radiologists in United States in 2006-2007 and trends since 1991-1992. Radiology 252(2):458-467

19. Dhanoa D, Dhesi TS, Burton KR, Nicolaou S, Liang T (2013) The evolving role of the radiologist: the Vancouver workload utilization evaluation study. J Am Coll Radiol 10(10):764-769

20. Rathnayake S, Nautsch F, Goodman TR, Forman HP, Gunabushanam G (2017) Effect of radiology study flow on report turnaround time. AJR Am J Roentgenol 209(6):1308-1311

21. Harolds JA, Parikh JR, Bluth El, Dutton SC, Recht MP (2016) Burnout of radiologists: frequency, risk factors, and remedies: a report of the $A C R$ Commission on human resources. J Am Coll Radiol 13(4):411-416

22. Kelly AM, Cronin P, Dunnick NR (2007) Junior faculty satisfaction in a large academic radiology department. Acad Radiol 14(4):445-454

23. Griffith B, Kadom N, Straus CM (2019) Radiology education in the 21st century: threats and opportunities. J Am Coll Radiol 16(10):1482-1487.

24. Levin DC, Parker L, Rao VM (2017) The recent losses in Medicare imaging revenues experienced by radiologists, cardiologists, and other physicians. J Am Coll Radiol 14(8):1007-1012

25. Schemmel A, Lee M, Hanley T et al (2016) Radiology workflow disruptors: a detailed analysis. J Am Coll Radiol 13(10):1210-1214

26. Willis MH, Friedman EM, Donnelly LF (2018) Optimizing performance by preventing disruptive behavior in radiology. Radiographics 38(6): $1639-1650$

27. Shanafelt TD, West CP, Sinsky C et al (2019) Changes in burnout and satisfaction with work-life integration in physicians and the general US working population between 2011 and 2017. Mayo Clin Proc 94(9):16811694.

28. Harolds JA (2019) Quality and safety in health care, part XLIX: mentoring, coaching, and burnout. Clin Nucl Med 44(7):566-567

29. Harolds JA (2019) Quality and safety in health care, part XLV: introduction to burnout. Clin Nucl Med 44(3):221-222

30. Levine MS (2004) Primer for clinician scholars in academic radiology. Radiology 231(3):622-627

31. Munk PL (2015) Mentoring: helping others do what they can, as well as they can. Can Assoc Radiol J 66(4):301

32. Jackson VA, Palepu A, Szalacha L, Caswell C, Carr PL, Inui T (2003) "Having the right chemistry": a qualitative study of mentoring in academic medicine. Acad Med 78(3):328-334

33. Maguire MA, Gore JC (2005) The current state of NIH funding of research in diagnostic radiology at U.S. medical schools. J Am Coll Radiol 2(5):436-443

34. Maynard CD, Nagy EC (2001) The academy of radiology research and the growth of NIH support for imaging research, 1995-2001. Acad Radiol 8(12): 1290-1293

35. Gifford WA, Davies B, Graham ID, Lefebre N, Tourangeau A, Woodend K (2008) A mixed methods pilot study with a cluster randomized control trial to evaluate the impact of a leadership intervention on guideline implementation in home care nursing. Implement Sci 3:51

36. Freel SA, Smith PC, Burns EN, Downer JB, Brown AJ, Dewhirst MW (2017) Multidisciplinary mentoring programs to enhance junior faculty research Grant success. Acad Med 92(10):1410-1415

37. Libby AM, Hosokawa PW, Fairclough DL, Prochazka AV, Jones PJ, Ginde AA (2016) Grant success for early-career faculty in patient-oriented research: difference-in-differences evaluation of an interdisciplinary mentored research training program. Acad Med 91(12):1666-1675

38. Spence JP, Buddenbaum JL, Bice PJ, Welch JL, Carroll AE (2018) Independent investigator incubator (I (3)): a comprehensive mentorship program to jumpstart productive research careers for junior faculty. BMC Med Educ 18(1):186

39. Kelly AM, Mullan PB (2018) Teaching and assessing professionalism in radiology: resources and scholarly opportunities to contribute to required expectations. Acad Radiol 25(5):599-609

40. Gunderman RB (2018) Portraits in professionalism: when radiologists break the law. Acad Radiol 25(5):681-682

41. Kelly AM, Mullan PB (2018) Designing a curriculum for professionalism and ethics within radiology: identifying challenges and expectations. Acad Radiol 25(5):610-618

42. Kaba R, Sooriakumaran P (2007) The evolution of the doctor-patient relationship. Int J Surg 5(1):57-65

43. Perry RE, Parikh JR (2018) Developing effective Mentor-mentee relationships in radiology. J Am Coll Radiol 15(2):328-333 
44. Sorkness CA, Pfund C, Asquith P, Drezner MK (2013) Research mentor training: initiatives of the University of Wisconsin Institute for Clinical and Translational Research. Clin Transl Sci 6(4):256-258

45. Pfund C, House S, Spencer $\mathrm{K}$ et al (2013) A research mentor training curriculum for clinical and translational researchers. Clin Transl Sci 6(1):26-33

46. Zerzan JT, Hess R, Schur E, Phillips RS, Rigotti N (2009) Making the most of mentors: a guide for mentees. Acad Med 84(1):140-144

47. Koopman RJ, Thiedke CC (2005) Views of family medicine department chairs about mentoring junior faculty. Med Teach 27(8):734-737

48. Ray CE (2012) Mentoring-it's all good, right? Semin Intervent Radiol 29(2): 69-70

49. Chopra V, Edelson DP, Saint S (2016) A piece of my mind. Mentorship malpractice. JAMA 315(14):1453-1454

50. Straus SE, Chatur F, Taylor M (2009) Issues in the mentor-mentee relationship in academic medicine: a qualitative study. Acad Med 84(1): 135-139

51. Rabatin JS, Lipkin M Jr, Rubin AS, Schachter A, Nathan M, Kalet A (2004) A year of mentoring in academic medicine: case report and qualitative analysis of fifteen hours of meetings between a junior and senior faculty member. J Gen Intern Med 19(5 Pt 2):569-573

52. Vaughn V, Saint S, Chopra V (2017) Mentee missteps: tales from the academic trenches. JAMA 317(5):475-476

53. Grajo JR, Retrouvey M, Awan $O$ et al (2019) Transitioning from radiology training to academic faculty: defining your role and interests. Curr Probl Diagn Radiol. https://doi.org/10.1067/j.cpradiol.2019.03.001. [Epub ahead of print]. PMID: 30929906.

54. Lexa FJ, Fessell D (2019) A devilish dilemma: formalized mentoring, or laissez-faire? J Am Coll Radiol. https://doi.org/10.1016/j.jacr.2019.05.037. [Epub ahead of print]. PMID: 31229441.

55. Harrison R, Anderson J, Laloe PA, Santillo M, Lawton R, Wright J (2014) Mentorship for newly appointed consultants: what makes it work? Postgrad Med J 90(1066):439-445

56. Benson CA, Morahan PS, Sachdeva AK, Richman RC (2002) Effective faculty preceptoring and mentoring during reorganization of an academic medical center. Med Teach 24(5):550-557

57. Bussey-Jones J, Bernstein L, Higgins $S$ et al (2006) Repaving the road to academic success: the IMeRGE approach to peer mentoring. Acad Med 81(7):674-679

58. Fleming GM, Simmons JH, Xu M et al (2015) A facilitated peer mentoring program for junior faculty to promote professional development and peer networking. Acad Med 90(6):819-826

59. Seritan AL, Bhangoo R, Garma S, Dube J, Park JH, Hales R (2007) Society for women in academic psychiatry: a peer mentoring approach. Acad Psychiatry 31(5):363-366

60. Cook DA, Bahn RS, Menaker R (2010) Speed mentoring: an innovative method to facilitate mentoring relationships. Med Teach 32(8):692-694

61. Robbins JB, Klein KA, Slanetz PJ (2019) Impact of a speed mentoring program in an academic radiology society. J Am Coll Radiol 16(5):754-756

62. Baker SR, Barry M, Chaudhry H, Hubbi B (2006) Women as radiologists: are there barriers to entry and advancement? J Am Coll Radiol 3(2):131-134

63. Spalluto LB, Spottswood SE, Deitte LA, Chern A, Dewey CM (2017) A leadership intervention to further the training of female faculty (LIFT-OFF) in radiology. Acad Radiol 24(6):709-716

64. Roubidoux MA, Packer MM, Applegate KE, Aben G (2009) Female medical students' interest in radiology careers. J Am Coll Radiol 6(4):246-253

65. Nattinger AB (2007) Promoting the career development of women in academic medicine. Arch Intern Med 167(4):323-324

66. Carr PA, Yamamoto T, Karmy G, Baimbridge KG, Nagy JI (1989) Analysis of parvalbumin and calbindin D28k-immunoreactive neurons in dorsal root ganglia of rat in relation to their cytochrome oxidase and carbonic anhydrase content. Neuroscience 33(2):363-371

67. Levinson W, Tolle SW, Lewis C (1989) Women in academic medicine. Combining career and family. N Engl J Med 321(22):1511-1517

68. Mark S, Link H, Morahan PS, Pololi L, Reznik V, Tropez-Sims S (2001) Innovative mentoring programs to promote gender equity in academic medicine. Acad Med 76(1):39-42

69. Files JA, Blair JE, Mayer AP, Ko MG (2008) Facilitated peer mentorship: a pilot program for academic advancement of female medical faculty. J Women's Health (Larchmt) 17(6):1009-1015

70. Levine RB, Mechaber HF, Reddy ST, Cayea D, Harrison RA (2013) "A good career choice for women": female medical students' mentoring experiences: a multi-institutional qualitative study. Acad Med 88(4):527-534
71. Beech BM, Calles-Escandon J, Hairston KG, Langdon SE, Latham-Sadler BA, Bell RA (2013) Mentoring programs for underrepresented minority faculty in academic medical centers: a systematic review of the literature. Acad Med 88(4):541-549

72. Cora-Bramble D, Zhang K, Castillo-Page L (2010) Minority faculty members' resilience and academic productivity: are they related? Acad Med 85(9): 1492-1498

73. Pololi LH, Krupat E, Civian JT, Ash AS, Brennan RT (2012) Why are a quarter of faculty considering leaving academic medicine? A study of their perceptions of institutional culture and intentions to leave at 26 representative U.S. medical schools. Acad Med 87(7):859-869

74. Yehia BR, Cronholm PF, Wilson N, Palmer SC, Sisson SD, Guilliames CE et al (2014) Mentorship and pursuit of academic medicine careers: a mixed methods study of residents from diverse backgrounds. BMC Med Educ 14:26

\section{Publisher's Note}

Springer Nature remains neutral with regard to jurisdictional claims in published maps and institutional affiliations.

\section{Submit your manuscript to a SpringerOpen ${ }^{\circ}$ journal and benefit from:}

- Convenient online submission

- Rigorous peer review

- Open access: articles freely available online

- High visibility within the field

- Retaining the copyright to your article

Submit your next manuscript at $>$ springeropen.com 